\section{rev Psi}

Revista de Psicología (UNLP)

https://revistas.unlp.edu.ar/revpsi

\title{
Daniel Tammet: el autista y los números
}

\author{
Silvia Elena Tendlarz ${ }^{1,2}$ \\ Correspondencia \\ stendlarz@fibertel.com.ar

\section{Filiaciones institucionales} \\ Argentina) / Asociación Mundial de
}

'Escuela de Orientación Lacaniana (EOL, $\quad \quad$ 2Facultad de Psicología, Universidad de Buenos

Aires (UBA, Argentina)

\section{Resumen}

En este micro-artículo se propone un examen de la afinidad particular de Daniel

Tammet, autista de alto nivel, con los números y las lenguas.

\section{Palabras clave}

psicoanálisis $\mid$ autismo $\mid$ números

\section{Proceso editorial}

Recibido

17 may. 2021

Aceptado

12 jun. 2021

\section{Publicado}

30 jul. 2021
Coordinadora del dossier

María Cristina Piro (Facultad de Psicología UNLP, Argentina).
ISSN

2422-572X

Licencia

Licencia de Cultura Libre CC-BY 4.0

(Compartir - Adaptar - Atribuir)

Entidad editora

RevPsi es una publicación de la

Facultad de Psicología (Universidad

Nacional de La Plata, Argentina) 


\section{Daniel Tammet: 0 autista e os números}

\section{Resumo}

Este microartigo propõe um exame da afinidade particular de Daniel Tammet, altamente autista, com números e idiomas.

\section{Palavras-chave}

psicanálise | autismo | números

\section{Daniel Tammet: the autistic and the numbers}

\section{Abstract}

This micro-article proposes an examination of high-level autistic Daniel Tammet's particular affinity with numbers and languages.

\section{Keywords}

psychoanalysis | autism | numbers 
El talento de algunos sujetos autistas calculadores y su particular relación con los números impacta a la opinión pública y produce un vivo interés. ¿De dónde surge esta habilidad? El testimonio de Daniel Tammet, autista de algo nivel, permite examinar esta cuestión.

\section{Amigo de los números}

En el libro El hombre que confundió a su esposa con un sombrero (Sacks, 1985/1988), el neurólogo Oliver Sacks relata su encuentro con unos gemelos autistas a fines de los años 1960 que tenían un talento particular para el cálculo. Michael y John mantenían entre ellos una comunicación singular puramente numérica. Uno de ellos decía un número de seis cifras y el otro respondía con otro número. Luego de anotarlos Sacks se interroga por la significación de esos números, si tenían un sentido real o universal o si era un sentido privado elaborado entre ellos. Para su sorpresa descubre que todos los números que intercambiaban los gemelos eran números primos. En matemática los números primos son aquellos que sólo pueden ser divididos por ellos mismos o por la unidad. Con la ayuda de una tabla de números primos les propuso entonces un número de siete dígitos. Los gemelos respondieron a esta propuesta y continuaron hasta llegar a los diez dígitos, pero esos números no aparecían en la tabla utilizada por Sacks puesto que no se conocían aún.

Jean-Claude Maleval, al estudiar en su libro El autista y su voz (Maleval, 2009) la relación de los autistas con los números primos, afirma que es un número que se abre al vacío como los elementos en química que no pueden descomponerse y parecen ser fundadores. No tiene más referencia que él mismo, por lo que se vuelve una "referencia fija", es decir, real. Frente al caos al que se confronta el autista, el número primo funciona como una referencia fija a partir de la cual ordenarse. De allí que se vuelve una fuente de satisfacción como lo demuestran los gemelos encontrados por Sack, o de una "belleza remarcable" como lo expresa Daniel Tammet que guarda también esta relación particular con los números primos.

Tammet, joven autista británico diagnosticado a los veinticinco años como sindrome de Asperger por Baron-Cohen, también posee una capacidad especial con los cálculos complejos matemáticos y con el aprendizaje de distintas lenguas. Cobró notoriedad cuando recitó 22.514 dígitos del número pi de memoria, durante cinco horas, para ayudar a la Asociación Nacional de Epilepsia, enfermedad que padeció en su infancia. Su capacidad muestra un orden intelectual que no pasa por la enunciación ni por el estorbo imaginario del sentido y de la relación con los otros.

En su narración testimonial plantea que su cerebro descompone todo en elementos tangibles y concretos, pero posee dificultades en la empatía, en la comunicación, o en una visión del conjunto sin perderse en los detalles. Los números tienen una forma, un color, una textura y una emoción. De manera instantánea ve los resultados de complejas operaciones matemáticas. Es una experiencia visual de los números puesto que son imágenes y patrones coherentes que le brindan seguridad. Desde el 
comienzo de su libro Nacido en un día azul explica que nació un miércoles y ese día para él era siempre azul. Su fecha de nacimiento, 31 de enero de 1979, tiene la forma suave y redondeada de los números primos: 31, 19, 197, 97, 79 y 1979. Esta cualidad es similar a los cantos rodados de las playas y le permite reconocer a todos los números primos hasta el 9973.

De niño su presentación correspondía al autismo infantil de Kanner. A los dos años se balanceaba y caminaba hasta la pared para golpearse la cabeza contra ella de manera repetida y rítmica. Llegaba a lastimarse. Tenía violentos berrinches. Era solitario, no jugaba, se aislaba. Necesitaba repetir los mismos recorridos en forma fija o gritaba. Se quedaba mirando una moneda que hacía girar repetidamente en el piso. Por momentos, se apretaba los oídos con los dedos para sumergirse en el silencio. En determinado momento su gusto por el orden lo lleva a ordenar los libros que se encontraban a su alrededor. Los páginas de los libros tenían números y se sentía feliz rodeado por ellos. Los números eran sus amigos y consideraba que cada uno tenía su propia personalidad. Comienza a leerlos antes de leer frases. Al contarlos los ve como movimientos o formas coloreadas en su mente. Cuando le costaba dormir se paseaba por sus paisajes numéricos. También las palabras las visualizaba en su cabeza basándose en las formas de las letras. De la misma manera que Temple Grandin (1998) tituló su primer libro Thinking in pictures [Pensar con imágenes], Tammet (2012/2013) titula su tercer libro Thinking in numbers, aunque cambia de título en su traducción, dando cuenta así de su particular relación con los números.

Durante su adolescencia se pasaba horas haciendo sumas, multiplicando un número por sí mismo. Para llenar el tiempo crea sus propios códigos sustituyendo letras por números, por ejemplo 211795362 cifraba la palabra Daniel. Vemos así la relación con la cifra en sus dos sentidos: cifrar para obtener un código fijo y la relación con los números.

Durante el recitado del número pi tuvo una experiencia particular. Recitó los primeros 10.000 dígitos durante dos horas, pero al llegar a los 16.600 dígitos, durante unos escasos instantes su mente quedó en blanco: no había formas, ni colores, ni texturas. "Es como si estuviese mirando un agujero negro...", dice (Tammet, 2006, p. 206). Al salir de esa oscuridad volvió el fluido de colores y siguió recitando para concluir a las cinco horas. Al recitar compartía el conteo de su soledad y la alegría que le producía la belleza de los números y sus colores (Tammet, 2013).

El número, para Lacan, tiene la particularidad de ser una excepción en lo simbólico puesto que pertenece al registro de lo real, es decir, no es ni imaginario ni simbólico. Esto permite explicar la particular relación del sujeto autista con el número en tanto que viven inmersos en lo real.

Eric Laurent se refirió en distintas oportunidades a la relación del autista con la cifra haciendo resonar la ambigüedad que comporta la cifra del lado de las estadísticas que calculan cuántos autistas existen en nuestro mundo contemporáneo, y la relación del autista con los números puesto que utilizan una lengua de cálculo. Hay una búsqueda en estos genios calculadores, llamados así por la aptitud que poseen algunos de ellos 
con el cálculo, de reducir la lengua a una cifra, a lo que hay de matemático en el significante. Se cruzan así las tentativas de la civilización de obtener cifras del autismo con la tentativa autista de reducir la relación con el Otro del significante a una cifra (Laurent, 2011). Los objetos de la realidad pueden remitir a algo que ocupa imaginariamente un lugar en el espacio; en cambio, la cifra, los números, como por ejemplo la raíz cuadrada del número 1 , no remiten a nada en la realidad. La relación con el número alivia al sujeto autista de la realidad y eso les permite una captación directa.

\section{De la lengua privada al escritor}

Daniel Tammet también tiene una relación particular con las lenguas. Habla once idiomas: inglés, francés, finlandés, alemán, español, lituano, rumano, estonio, islandés, galés y esperanto. Aprendió islandés en una semana para mostrar su capacidad de aprendizaje de idiomas durante el documental que se hizo sobre él. Es más, creó una lengua llamada Manti a partir de mezclar el finlandés y el estonio.

En su modalidad de funcionamiento, cada frase la escucha en forma literal. Las abstracciones le resultan menos fáciles de entender, por lo que guarda una imagen de cada una de ellas para que le ayude a deducir su significado. Aprende los idiomas, pero no llega a comprender totalmente el sentido por el efecto de literalidad que lo sustrae de los efectos metafóricos y los sentidos evocados. Cuando lee o escucha que algo es complejo lo imagina en partes distintas que necesitan unirse para alcanzar una respuesta. La imagen que ve lo ayuda a comprender.

Encontramos en Tammet un trabajo relativo a su funcionamiento autista: el doble como suplencia, su habilidad en el aprendizaje de las lenguas pero con una reducción del sentido a su literalidad y al Uno de goce, y, por último, la relación real que mantiene con los números y las cifras que funcionan como series iterativas en su isla de competencia. Este trabajo sobre el borde conlleva una invención propia del sujeto. Pero como contrapunto de la serie iterativa de los números y de las letras aparece un agujero negro durante el recitado del número pi que pone en evidencia la función de borde que ocupa la serie, la iteración de los cálculos, la secuencia de los números y de las letras.

La relación con el número, la cifra y el cálculo da muestras de su funcionamiento singular iterativo del Uno de goce. Tammet, dice Laurent, "logra apaciguar su angustia dando a cada cifra un color particular, el sistema discontinuo de los colores aporta entonces un color de vida al puro cifrado" (Laurent, 2013, p. 128).

De esta manera, como contrapunto a la forclusión del agujero, aparece la función de borde que ocupa la serie, la iteración de las secuencias, de los números y de las letras.

En lugar de la lengua común hablada, Tammet hace existir un lenguaje privado sin equívocos, cargado de un goce excepcional que puede provocar emociones intensas. Durante una entrevista que se le realizó en el Coloquio de autismo en Rennes en 2018 expresó que ya no tiene necesidad de pasar por un lengua inventada. Ahora se 
volvió escritor y forjó su lengua propia en sus libros. De allí que Laurent señala que el lenguaje privado no es una barrera autística para la comunicación sino que es un borde transitorio hasta que pierde su especificidad.

Concluyamos entonces con el final del poema de Tammet "El universo y yo":

"¿Qué es un vida?

Momentos suspendidos al infinito:

la música del viento en los árboles,

las sonrisas que enmarcan las ventanas,

el perfume caliente y terroso del café.

Pequeñas nadas por miles,

millones, mil millones

catorce mil millones

y más aún".

\section{Referencias}

Grandin, T. (1998). Thinking in pictures. Vintage Books.

Laurent, E. (2011). El sentimiento delirante de la vida. Colección Diva.

Laurent, E. (2013). La batalla del autismo. Grama.

Laurent, E. (2019). El sujeto autista y el automaton de lo escrito. Presentación en Colloque Autisme: Numérique et Robotique. Quel Partenaire Privilégié au 21e Siècle. Université Rennes 2. HTTPS://PSICOANALISISLACANIANO.COM/2019/11/ O7/ELAURENT-SUJETO-AUTISTA-AU TOMATONESCRITO-20191107/

Maleval, J.-C. (2009). L'autiste et la voix. Seuil.
Sacks, O. (1985/1988). L'homme qui prenait sa femme pour un chapeau. Seuil.

Tammet, D. (2006). Nacido en un día azul. Editorial Sirio.

Tammet, D. (2012/2013). L'éternité dans une heure. La poésie des nombres. Éditions J'Ai Lu.

Tammet, D. (2018). Portraits. Blancs Volants Editions.

Tendlarz, S. (2016). Clínica del autismo y de la psicosis en la infancia. Colección Diva.

Tendlarz, S. (2016) El autista y los números. Anuario Congreso UBA 